\title{
“CRISIS" AS TOOL IN THE DIGITAL GAMES INDUSTRY: RESISTANCE OR COMMAND AND CONQUER?
}

\author{
By Owen Livermore
}

From media-driven moral panics to colossal business failures, digital games have historically been rife with crisis, defining the games industry and its practices to a significant degree. More recently, media discourse regarding the very aggressive global economic crisis is host to an ideological game where the form and context of crisis is shaped into a number of disparate and sometimes contradictory conclusions about the current state of digital game development. I will provide an overview pinpointing some of the recent claims made about the digital games industry and relate this discursive context to the ongoing challenges of the people who work within it. Additionally, in an effort to address the title and theme of the Intersections 2009 Conference, I wish to highlight the ways in which crisis can be "disruptive", but also manipulable and productive in ways that reveal both hegemonic industry mandates and opportunities for bottom-up mobilization.

While many of these contexts of production speak to the crucial role of crisis in capital as expounded in Marxian critique, the ongoing struggles surrounding the digital games industry reveal diverse and often conflicting ways of utilizing crisis as a means of advancing various positions. An understanding of how the digital games industry can be transformed or subverted by crisis requires a comprehension of how the idea of "crisis" is deployed. What is clear is that crisis, both in terms of the digital games industry and labourers working within and around the industry, is not an external phenomenon that begins "somewhere else"; it develops and is 
developed by the production and circulation of digital commodities and corresponding circuits of struggle and negotiation.

David Harvey argues that the more current context of flexible accumulation itself developed from a number of economic crises beginning in the late 1960s. This new system, spurred on by dwindling product demand and declining profitability in an increasingly global marketplace, addresses the perceived rigidities of production, distribution and the acquisition and retention of labour. Post-Fordism "rests on flexibility with respect to labour processes, labour markets, products, and patterns of consumption. It is characterized by the emergence of entirely new sectors of production, new ways of providing financial services, new markets, and, above all, greatly intensified rates of commercial, technological, and organizational innovation" (Harvey 147). Perhaps not surprisingly, this system necessarily invokes tight controls on the nature and conditions of labour. Any number of strategies are implemented to devalue labour power, such as the creation of the Export Processing Zone (EPZ), which limits or bans unionization, geographical separation and isolation within production, outsourcing to take advantage of regional laws, tax shelters or trade agreements, and short-term contract work with little to no job security that heightens the precariousness of work. All of these practices are present to some degree within the digital games industry.

The current economic context has exposed the critical importance of finance capital to the world economy, not to mention its status as a highly integrated and networked monoculture. It is the case that money circulates and accrues through finance capital by gaining interest and investing in futures. However, it is a basic claim of Marx that, isolated and by itself, no surplus value is created in these types of transactions (i.e. money made somewhere is lost somewhere 
else). For modes of capital in which buying and selling of commodities takes place, the Marxian argument is that the indefinite circulation of commodities (or the intent to do so) through buying and selling allows capital to become a totalizing system. In Capital Vol.1, Marx writes that "the circulation of money as capital is an end in itself, for the valorization of value takes place only within this constantly renewed movement" (253). However, under these conditions, the valorization of value (or the creation of surplus value) can only come about through the acquisition and potential manipulation of labour-power. Using this rationale, the moment and context in which the labourer sells his or her labour power is crucial. This sentiment has been taken up by writers in the autonomous Marxist tradition, for whom the position and autonomy of the worker operates as a central organizing principle. As a "bottom-up" theoretical tradition, autonomists cultivate close relationships with and explore the collective possibilities in worldwide worker's organizations and movements. One common critique of the approach used by autonomist writers is that they foreground the autonomous labourer and their capacities at the expense of the Marxian dialectic and of the circulatory processes of capital's production and reproduction. However, I don't consider the gap as wide as some may think, as the capacity for workers to uncover and understand the conditions of their labour is of no less importance to Marx. One useful concept developed by the autonomist writers is "immaterial labour". In the interest of brevity, Maurizio Lazzarato (1996) offers up a succinct definition of the term, so I will include it here:

On the one hand, as regards the "informational content" of the commodity, it refers directly to the changes taking place in workers' labor processes in big companies in the industrial and tertiary sectors, where the skills involved in direct labor are 
increasingly skills involving cybernetics and computer control (and horizontal and vertical communication). On the other hand, as regards the activity that produces the "cultural content" of the commodity, immaterial labor involves a series of activities that are not normally recognized as "work"—in other words, the kinds of activities involved in defining and fixing cultural and artistic standards, fashions, tastes, consumer norms, and, more strategically, public opinion. (133)

As prototypical immaterial labourers, workers in the digital games industry have shed light on the exclusionary, exploitative and precarious conditions of their work. The infamous "EA Spouse" posting is one such example, which expressed distaste for digital game labour long before the current global economic crisis. Posted in November 2004 to a LiveJournal blog, the blogger "EA Spouse" describes in great detail the harsh yet typical working conditions experienced by his or her partner, an Electronic Arts (EA) employee in British Columbia (EA Spouse). As Dyer-Witheford and de Peuter describe in their writing on the "EA Spouse" posting and its subsequent reverberations, it served as a wake-up call to immaterial labourers in the digital games industry, especially since EA is regarded as one of the top digital game developers in the world (599-600). The article goes into great detail in describing the "dark side" of digital game labour and the tactics used by employers to retain and control their employees. Contracts with restrictive clauses, moves to protect intellectual property (which sometime implicates workers), and "forced workaholism" were exposed as commonplace industry practices (611).

There are strong hints that the looming global financial crisis presents immediate and long-term challenges for companies and even tougher times for workers. Big players such as Microsoft, Electronic Arts, THQ and Activision-Blizzard posted substantial quarterly losses in 
2008, even though total revenues were either unchanged or slightly improved over previous years. The high cost of game development, a large percentage of which is labour costs, is cited as the main source for the financial strain (Papineau). In an effort to mitigate both the losses and the potential risk involved in game development, game studios tend to focus and consolidate their attention and resources to developing previously established intellectual property and cutting or delaying projects that represent new or innovative creative endeavours. In addition, recent reports of the performance of the industry have cited waves of layoffs as evidence of a widespread effort to cut costs quickly. In late 2008, Electronic Arts announced 600 layoffs (for starters) in its worldwide operations, a figure that represents roughly six per cent of its workforce, while simultaneously lowering revenue projections for 2009 ("Electronic Arts Cutting Jobs"). Not surprisingly, EA stock plummeted soon after the news.

Another strategy employed by the bigger companies is to shut down smaller, previously acquired game design studios, as EA did in the winter of 2008 with Vancouver's Black Box. (Hartley). As studios deal with cost-cutting efforts and restructuring plans throughout their global operations, subsequent shortages in labour power and strain on workers create a damaging ripple effect throughout the industry. Production timelines may be rushed in critical stages in the game development process, such as the time-intensive but no less essential beta-testing phase, ultimately forcing an inferior product to enter the market prematurely. In the long term, industry commentators note that such strategies risk a diminishing consumer confidence in the games offered by specific studios. "There is a purported crisis of creativity in video game development due to practices such as risk aversion with the deployment of recognized game genres and 
franchise-based production and marketing. Some observers point to a stagnation in the variety of new releases as a reason to be pessimistic about continued profits in the industry" (Reisinger).

However, in spite of this evidence, there is a parallel and persistent rhetoric put forth in print, television and online media that the digital games industry is somehow "recession-proof". Industry research firms are keen to make it known that sales in the United States increased in 2008 by fifteen per cent and that sales for January 2009 were up thirteen per cent from the same time in the previous year (Caroom). Industry observers point to this new high score in sales statistics and a number of aggressive acquisitions in the industry as a sign of strength. Industry luminaries such as Nintendo president Satoru Iwata happily assert that the digital games industry is "less susceptible to the changes in the economy" and announce the intention to expand during the global downturn (Kohler). Much of this optimism is based on industry interpretations of demographics in different global markets and shifts in consumption that tend to occur in the event of an economic downturn. It is argued that the traditional consumer base for digital games has a much higher percentage of disposable income than other demographic groups, and will thus continue their consumption patterns unabated. Those consumers who suddenly find themselves unemployed will use their newly-found leisure time to splurge in a "relatively cheap form of entertainment that can be consumed at home" (So-eui and Martinez, "Play On").

Amidst all of this rather conflicting information comes the notion that the digital games industry is attempting to foster a climate that leads to increased financial backing in the form of venture capital. An article in The Globe and Mail describes the desire by game developers, especially the smaller independents, to seek out venture capital, which would represent a shift in the way that game development is initiated and conducted: 
"Typically, the creation of a video game is funded by publishers, who either own the studio developing the game, or provide milestone payments to the independent developers contracted to make the game. Under that model, publishers assume all the risk - whether the game gets made, whether it ships on time, whether it's a financial success - and as a result require developers to give up not just the majority of potential profits, but often also ownership of the intellectual property behind the title" (Kyllo).

Needless to say, all the talk of digital games as "recession-proof" commodities would resonate strongly with investors and ventures firms alike, even though historically all but the biggest blockbusters fail to turn a profit.

One rather remarkable article in Slate Magazine concludes that the global recession is not a factor in the recent quarterly losses, layoffs and studio closures. Rather, the fault lies in the high costs incurred by game developers who have a large stable of contract employees working consistently on various projects. The article calls for a "Hollywood model" in which workers are hired for one project only and then released when that project has reached completion (Van Zelfden). While such a strategy attains the sort of flexibility desired by industry, it would only further intensify the precariousness of workers in the non-unionized industry, the majority of which work on a contract basis.

If the current system is untenable, what kind of production model is cited as a preferred means for game developers to cut development costs? The Slate article offers up the example of Valve Corporation's Portal, the unexpectedly successful multi-platform game released in 2007. 
The game is remarkable for its unique concept and story, all-female cast, and use of a game engine originally designed for a first-person shooter (Valve's Half-Life 2) to create an innovative puzzle game. Perhaps most importantly, the concept for Portal began with a game called Narbacular Drop, developed by students at the DigiPen Institute of Technology located in Redmond, Washington. After the game was released to limited critical acclaim, it was acquired by Valve Corporation, along with the development team. The same team went on to develop Portal, which was subsequently distributed widely by Electronic Arts and Steam, Valve's own online digital distribution platform.

Interestingly, the above example implicates the growing relationship between the digital games industry and educational institutions as a key to profitability through cost-cutting. In this case, cost-cutting means looking for new channels for digital labour power and the creative energies contained therein that elevate the role of educational institutions in research and development. I find that this relationship is intensifying with the formation of professional degree programs that encourage targeted research and development (through internships, research contracts and the like) and the cultivating of skill and knowledge sets that serve the immediate needs of the industry, skills that correspond to middle management "project leaders" who are able to oversee multiple aspects of game development. All of this addresses a crisis of labour cited by industry figures who identify a critical need for a more specialized (and larger) labour pool. These professional degree programs are in their early stages in Canada, but are already considered viable education models that can be replicated in other areas.

Is there room in these educational structures for students to take stock of the issues quickly confronting them as digital labourers, and is there space for students/workers to come 
together in meaningful ways to address these issues? The autonomist writers would claim that the in-between space that immaterial labourers occupy and their "mass intellectuality" enable a tremendous opportunity to focus energies in ways not prescribed by industry or institution (Lazzarato 1996). The same intellectual energies that make digital game development (and the industry as a whole) possible can be used to counter tendencies within the industry and mobilize resistance. Obviously, the site and the context in which those energies are honed are absolutely crucial. With an industry potentially weakened there lies the chance for workers in the digital games industry to seek new forms of organization and new ways to apply their immaterial labour. This movement finds kindred spirits in already occurring practices such as hacker and mod culture, game piracy, and subaltern virtual communities which have the capacity to serve more than a functional role at the intersections of capital.

\section{$\underline{\text { Works Cited }}$}

Caroom, Eliot. “In a Recession, It's Fun and Games.” Inc.com Feb. 122009.

http://www.inc.com/articles/2009/02/gaming.html 1 Mar. 2009.

Dyer-Witheford, N., and Coleman, S. (2007). Playing on the Digital Commons: Collectivities, Capital and Contestation. Media, Culture \& Society, 29 (6), 934-953.

Dyer-Witheford, Nick, and Greig de Peuter. “'EA Spouse' and the Crisis of Video Game Labour: Enjoyment, Exclusion, Exploitation, Exodous." Canadian Journal of Communication 31 (2006): 599-617.

EA Spouse. (November 10, 2004) EA: The Human Story. LiveJournal. April 4, 2009. 
http://ea-spouse.livejournal.com/274.html

“Electronic Arts Cutting Jobs.” CBC News Online 31 Oct. 2008.

http://www.cbc.ca/technology/story/2008/10/31/eacuts.html 1 Mar. 2009.

Hartley, Matt. "EA to Shutter Black Box Studio.” The Globe and Mail Online 19 Dec. 2008. http://www.theglobeandmail.com/news/technology/article728877.ece 5 Mar. 2009.

Harvey, David. (1990). The Condition of Postmodernity : an Enquiry Into the Origins of Cultural Change. Cambridge, MA: Blackwell.

Kohler, Chris. "Nintendo's Iwata: How to Expand in a Recession.” Wired.com Feb 52009. http://www.wired.com/gamelife/2009/02/nintendos-iwata/ 2 Mar. 2009

Kyllo, Blaine."Looking for a new way to invest? Make a game of it" The Globe and Mail Online 12 Mar. 2009 http://www.theglobeandmail.com/news/technology/article312162.ece 2 Mar. 2009

Lazzarato, Maurizio. 'Immaterial Labor', trans. Paul Colilli and Ed Emory in Radical Thought in Italy: a Potential Politics, edited by Paolo Virno and Michael Hardt (Minneapolis: University of Minnesota Press, 1996), 133-147.

Marx, Karl. (1976). Capital, Volume I. London: Penguin.

Papineau, Brian J. "Video Game Companies Rethink Innovation in Tough Economy.” Digital 
Journal 9 Feb. 2009. http://www.digitaljournal.com/article/266887 2 Mar. 2009.

"Play On: Video games have proved to be recession-proof—so far, at least." The Economist 18 Dec. 2008.

Reisinger, Don. "Bad Economy Means Lame Games." CNet News 5 Feb 2009. http://news.cnet.com/8301-13506_3-10157402-17.html 1 Mar. 2009.

So-eui, Rhee and Jennifer Martinez. "Online games look for gains from recession." New York Times Online 2 Feb. 2009. http://www.nytimes.com/2009/02/02/business/worldbusiness/02ihtgame.1.19860447.html 2 Mar. 2009.

Van Zelfden, Evan. "What's Killing the Video-Game Business." Slate.com Feb. 162009 http://www.slate.com/id/2210732/ 2 Mar. 2009. 